\title{
The Newest Borrowed Words and Methods of their Formation in the Russian- and Chinese-Language Internet Communication Space
}

\author{
Ke Zhang \\ Faculty of Philology, Peoples' Friendship University of Russia (RUDN University), Moscow, \\ RUSSIA \\ (D) 0000-0002-7765-2133 D-7768-2019 \\ Vladimir N. Denisenko \\ Faculty of Philology, Peoples' Friendship University of Russia (RUDN University), Moscow, \\ RUSSIA \\ (D) 0000-0001-6021-4068 SC 57193133860 A- A $6522-2017$
}

\section{Elena B. Ponomarenko}

Faculty of Philology, Peoples' Friendship University of Russia (RUDN University), Moscow, RUSSIA

(D) 0000-0003-3181-507X SC 57191415307 D-8088-2019

\section{Marina R. Zheltukhina}

Institute of Foreign Languages, Volgograd State Socio-Pedagogical University, Volgograd, RUSSIA (D) 0000-0001-7680-4003 SC 56669701900 A-7301-2015

zzmr@mail.ru

\section{Anastasia V. Denisenko}

Engineering Academy, Peoples' Friendship University of Russia (RUDN University), Moscow, RUSSIA

(iD) 0000-0002-0222-5460 D-7770-2019

Oksana V. Shiryaeva

Department of Russian Language for Foreign Students, Southern Federal University, Rostov-onDon, RUSSIA

(D) 0000-0002-7846-2702

\section{ARTICLE INFO}

Received: 19 June 2019

Accepted: 9 September 2019

Published: 9 September 2019

DOI: https://doi.org/10.29333/ojcmt/5930

ABSTRACT

The article elaborates on a comparative analysis of the methods of borrowing (phonetic, semantic, graphic) foreign words in the modern Russian and Chinese languages. The emphasis is upon the gaming methods of formation of units occurred because of borrowing of foreign language vocabulary within the last 10 years, spread in the Internet but not recorded in any dictionaries, as well as upon the peculiarities of their functioning in the Russian- and Chinese-language Internet communication space. In the research, the following techniques are used: observation, description, classification and contrastive comparison. It is established, that an important feature of the newest borrowed words used by the Russian and Chinese Internet users is that predominantly American English constitutes the source language. Similarities and differences in the Russian- and Chineselanguage Internet communication are revealed.

Keywords: borrowed word, borrowing method, Internet communication, language game Copyright ( 2019 by OJCMT

ISSN: $1986-3497$ 


\section{INTRODUCTION}

Being the most accessible way to provide, search, store and transmit unlimited information, the Internet quite rapidly evolved from an information resource into a communication environment, as well as promptly provides communication between people, including the intercultural one.

Lexical borrowing does not mean the insufficiency of the word-forming means of any language, but primarily evidences the linguistic contacts of peoples and countries in the course of development of various spheres of the social activity. The language of communication in the Internet space is actively enriched by borrowed words from other languages being the object of conscious word creation - many foreign-language lexical units are borrowed by gaming methods for emotive and evocative expression of Internet users as well as their creative self-expression.

According to M.R. Zheltukhina, "the new effective mediated two-way communication is implemented due to the intensive development of information technologies and the global Internet, stipulating the creation of mass social networks and other communication products in the Internet space" (Zheltukhina, 2010, p. 12). Some scientists note that language norms are under shift, the language is rich in neologisms, jargonisms and profane language. The researchers are particularly concerned about the predominance of the borrowed vocabulary as well as the use of youth Internet jargon in media texts (Tameryan et al., 2018a, 2018b, 2019; Volskaya, 2018; Zheltukhina et al., 2017, 2018, 2019).

\section{LITERATURE REVIEW}

According to Minakova, Ponomarenko, and Talybina, one may identify two main points of view in relation to this problem while considering the topics of works dedicated to borrowing. Firstly, this is the process of penetration of a significant layer of the foreign vocabulary into the Russian language fraught with a certain peril, but the foreign language vocabulary dynamic incorporation into the language system is simultaneously determined by some extralinguistic reasons. Secondly, these units are claimed by society and serve the needs thereof, thus enriching the language. The "need principle" of such language units is noted to take the first place (Aleshchanova, Frolova, \& Zheltukhina, 2018; Minakova, Ponomarenko, \& Talibina, 2018, p. 139).

The studies of English, Russian and Chinese linguists in the field of lexicology, lexicography, neology and borrowing theory, notably Haugen (1950), Serjeantson (1962), Bussmann (1999), Crystal (2008), Krysin (2004, 2010), Semenas (2000), Marinova (2012), Lo Changpei and Hu Shuangbao (2009), Shi Youwei (2004, 2013), Zhao Yuanren (2012), Zhang Ke and Denisenko (2018) constituted the theoretical and methodological basis hereof. Taking into account the traditional understanding of the borrowing issue as well as the views of modern linguists, we consider borrowing as a process of transition of a language unit from one language to another one as well as the process of formation of a new language unit in a language influenced by another language due to one or more linguistic contacts. Thus, adhering to the broad understanding of the borrowed word term, we consider the lexical units formed due to the lexical borrowing as borrowed words.

The lexical units compiled by the article author by the continuous sampling of the borrowed words dictionaries and text messages of the Russian-language and Chineselanguage Internet forums devoted to the common topic discussion constituted the study material, notably the "iXBT Conference" (http://forum.ixbt.com) in the "Other forums" 
part (forums for topics not to be discussed in other thematic forums) in the Russianlanguage Internet forums as well as the "Tianya (天涯 “Universe”)" (http://bbs.tianya.cn) in the "Liaovan Tianya (了望天涯 "hot spot on the Tianya forums")" part (forums for the most discussed topics) in the Chinese-language Internet forums. The study included the following techniques: observation, description, classification and contrastive comparison.

\section{RESULTS AND DISCUSSION}

The Russian language and the Chinese language borrow foreign words by phonetic, semantic and graphic methods. Both languages have various gaming methods for creating neologisms while borrowing lexical units from foreign languages. The newest borrowed words formed by the language game and applied by users during the Internet written communication have some features of the conversation vocabulary.

Phonetically borrowed Words in the Russian-Language and Chinese-Language Internet Space

A phonetically borrowed word means a lexical unit where the sound and meaning of a word in one language are established in another language due to the phonetic borrowing (Bynon, 1977; Gao Mingkai \& Liu Zhengyan, 1958; Marinova, 2012; Sapir, 2006, 2000).

The mainstreaming of new information and communication technologies, rapid spread of the Internet, continuous increase in the number of network resource users resulted in the international computer terminology emergence. In case where there is a need to use some foreign language concepts, names of new realities or objects not existing in the original language environment, the Russian language often borrows lexemes (lexical items) of approximate sound and similar meaning from other languages. For example, the Russian words used in the field of information and communication technologies are phonetically borrowed from English in the vast majority of cases: монитор (English monitor), ббайл (English file), pоymep (English router), caŭm (English site), форум (English forum) (Kuznetsov, 2009: http://slovari.gramota.ru/), etc.

The Internet communication space has a tendency of increase in the number of words phonetically borrowed from the English language, semantically equivalent to the words existing in the Russian language. The borrowing method, where only the sound shell is basically borrowed and the language fails to obtain a new lexical meaning but only a new sound, constitutes a specific feature of the Internet communication language, especially among young people. Therein, the general tendency for using English borrowed words in everyday speech has obviously taken place; young people consider the use thereof as a sign of modernity. For example, мэн/лен (English man); мани (English money); сайз (English size); слайл, слайлик (English smile); лузер (English loser) (Avanesov \& Ozhegov, 2007: http://wordsonline.ru/). The main function of such words is expressive one; they increasingly replace the native language everyday words or expressions from the young people's speech. Many of them eventually become well known and are used by an increasing number of Internet users regardless of their status, education, age or nationality.

The phonetically borrowed vocabulary is represented not only by nouns but also by other parts of speech in the communication of Internet users. Thus, for example, verbs assume Russian verbal suffixes -a(mь): acкать (English ask), спикать (English speak); $u(m ь)$ : апгрейдить (English upgrade), коннектиться (English connect) (Online Dictionary of modern vocabulary, jargon and slang, 2014: https://argo.academic.ru/). The verbs derived from the borrowed roots may form aspectual pairs. For example, a word 
K. Zhang, et al.

лукать “смотреть" (imperfective aspect) and полукать/лукнуть (perfective aspect) from the English word look (Online Dictionary of modern vocabulary, jargon and slang, 2014: https://argo.academic.ru/). Adjectives may also be borrowed with the help of Russian suffixes and endings. For example, блуевыцй (English blue), фбайный/ байновый (English fine). Adverbs such as кул (English cool), вэри (English very), нэва (English never). Interjections such as вay (English wow), ec (English yes) (Online Dictionary of modern vocabulary, jargon and slang, 2014: https://argo.academic.ru/).

The sound form of a foreign language word or the external phonetic shell thereof is reproduced in case of the phonetic borrowing method (Duanmu 2007, p. 32). This borrowing method has long been widespread both in the Russian and Chinese languages, since it accurately conveys the source word meaning. English has become the main source of phonetically borrowed words at the present stage of the Chinese language development. For example, 逻辑 [lo tszi] (English logic); 克隆 [ke lon] (English clone); 丁克 [din ke] (English DINK, Double Income No Kids) (Modern Chinese Dictionary (7th edition), 2016: http://www.cidianwang.com/).

The Chinese language breaks the sounds of foreign words into syllables and records each syllable with a hieroglyph in case of the phonetic borrowing. As is known, the syllabic nature of the Chinese language means that each syllable has certain meanings determined by the relevant hieroglyphs in writing. Due to the semantic significance of each syllable determined by hieroglyphs, the hieroglyphs themselves are related to certain meanings assigned thereto and may not serve only as the sounds (syllables) phonetic recording means not taking the assigned own meanings thereof in the phonetically borrowed words. In most cases, the phonetically borrowed word fails to convey the semantic content of the borrowed word in the hieroglyph image thereof, the rule of syllabic division semantic significance is not effective in this case.

However, the use of phonetically borrowed words from the English language has become a particular fashion trend in the Chinese-language Internet communication in recent years caused by the stereotypes and ideals popular among young people. Such popular foreign words have their own linguistic life in the system of lexical means being actively formed in the Internet environment conditions, for example: 马克 [ $\mathrm{ma} \mathrm{ke]} \mathrm{(English}$ mark); 哈皮 [ha py] (English happy) 撸瑟/ 卢瑟 [lu se] (English loser) (Baidu Encyclopedia, 2008: https://baike.baidu.com/). Some phonetically borrowed words have a figurative meaning with a special semantic styling in the Internet, for example, the word逼格 [bi ge] is borrowed from the English word bigger by the phonetic method (in the "bigger than bigger" iPhone advertising slogan) and is used in the meaning of the "one having a particular experience of pretending" (Baidu Encyclopedia, 2008: https://baike.baidu.com/). The use of this word evidences the Internet users' intention to satirize the people willing to buy something not corresponding to their financial status for the purpose of garnering attention.

Semantically borrowed Words in the Russian-Language and Chinese-Language Internet Space

One may appropriately call calquing (one of the borrowing methods) as a semantic borrowing and a calque itself as a semantically borrowed word (Krysin, 2004, p. 221; Ge Benyi, 2002, p. 13; Richards \& Schmidt, 2010). The semantic borrowing means conveying the semantic structure or semantic content of the source language words. Therein, the 
idea itself and the derivation principle but not the lexical means of the implementation thereof are borrowed.

The Russian language lexical calques are generally divided into two groups, notably structural (derivational) and semantic ones in accordance with the calquing methods. One may distinguish lexical structural calques (derivational ones according to the Russian linguists - the derivational composition of a foreign word is calqued) and selectional calques (combination of words is created by translating foreign phrases) (Krysin 2004: 223), for example: проигрыватель (English player), автообновление (English autoupdate), материнская плата (English motherboard), рабочая станиия (English workstation) (Kuznetsov, 2014: http://gramota.ru/).

Semantic calques are formed under the influence of a foreign language due to reinterpreting the old words' semantics (Reformatsky, 1996). The Russian language allows the meaning introduction of the semantic equivalent word from another language, and the already existing word subsequently obtains some secondary (figurative) meanings (Krysin, 2004, p. 224). We found some Russian words or some words borrowed into the Russian language long ago used in the slang meaning of foreign lexical units or phrases in the forum messages. We consider these words to be semantic calques in Russian slang, in particular in the Internet communication language. The calquing of the source word slang meaning is based on the similarity thereof with the calqued word in accordance with the basic meaning. For example, the Russian word зеленые/зелень is used in the meaning of "American dollars", supposedly under the influence of the "money" slang meaning of the English word green (Online Dictionary of modern vocabulary, jargon and slang, 2014: https://argo.academic.ru/).

Russian words or the words borrowed by the Russian language that sound similar to foreign ones may be used in the meaning of the corresponding prototypes. We consider such words as special lexical calques appeared due to a peculiar play on sounds. A lot of words of this group may be found in the field of computer and network technologies, notably the words borrowed from neutral vocabulary on the basis of phonetic association assume the terminological meanings of foreign terms. For example, елеля/лыло (English e-mail) - "electronic mail"; дрова (English drive); каша (English cache) (Online Dictionary of modern vocabulary, jargon and slang, 2014: https://argo.academic.ru/). Slang vocabulary is similarly created in the youth environment: the word гудовый with the meaning "good" (English good) was created through the sound adaptation; gbakup (literally fakir in English) as a consonant word to the English obscene word fucker is used in the meaning thereof (Online Dictionary of modern vocabulary, jargon and slang, 2014: https://argo.academic.ru/).

According to some linguists (Hu, 2004, p. 35; Hu \& Xu, 2003, p. 319: Miao, 2005; Shi Youwei, 2013), the morphological significance of syllabic division common to the Chinese language predetermines the predominance of calquing as a method of lexical borrowing. Unlike most phonetic words, calques are always meaningful and conveniently included in the lexical system of a language. The feeling of a foreign language of the created word is eventually lost, and it becomes habitual, allegedly a word of the own language.

In case if the structure of a borrowed word is distinct and the significant components thereof may be distinguished, Chinese usually translate it in parts, whereby "structural calques" appear in the Chinese language (Krysin, 2004; Reformatsky, 1996). For example, 马力 [ $m a l i]$ (English horsepower, where “马” [ma] "horse” + “力” [li] “power”; 热裤 [je ku] 
K. Zhang, et al.

(English hot pants), where “热” [je] “hot” + “裤” [ku] “pants” (Modern Chinese Dictionary (7th edition), 2016: http://www.cidianwang.com/).

A significant number of calques appear in the Chinese language denoting foreign words irrespective of the structure thereof, this group of calques may be determined as "etymological calques" (Potebnya 1889), since they "etymologize" (Potebnya 1889) translatable foreign words as well as descriptively convey their meanings. For example, the word 论坛 [lun'tan'] (English forum) is formed through combining the components “论 " [lun] "discussion" and “坛” [tan] "platform, tribune", where the word 论坛 is literally translated as the "platform for discussion" (Modern Chinese Dictionary (7th edition), 2016: http://www.cidianwang.com/).

The Chinese language also has some new semantic calques, for example: the Chinese word 钓鱼[diao $y u y$ ] (original meaning: "go fishing") obtained the figurative meaning "Internet fraud" influenced by the English word phishing (Wang Lei, 2012: http://www.cidianwang.com/); 瓶颈 [pin'tszin] (original meaning: "bottle neck") in the new meaning "key problem in the course of business" is semantically borrowed from the English prototype bottleneck (Modern Chinese Dictionary (7th edition), 2016: http://www.cidianwang.com/).

Adoption of a new meaning may also be based on a random phonetic similarity of the calqued word and the foreign-language prototype thereof, for example, 粉丝 [fen' sy] generally means "Chinese cellophane (glass) noodles from soybean or pea starch", due to the fact that the sound thereof is similar to the English word fans, the word 粉丝 is currently used in modern Chinese speech in the meaning of "fan(s)" as well (Modern Chinese Dictionary (7th edition), 2016: http://www.cidianwang.com/). The word 碧池 [bi chi] (original meaning: "a reservoir of pure water") similarly enriched the semantics from the English word bitch with the meaning of the "fast woman" (Baidu Encyclopedia, 2008: https://baike.baidu.com/).

It is worth mentioning that such words sounding similar to foreign words and used in the meaning of the same foreign words appear due to the "purposeful" sound association among the Chinese people for the purpose of providing the words with a new, modern and expressive sensation. Thus, the word 粉丝 [fen'sy] is not derived from the English word fans, it may be referred to the type of the words "consonant with foreign words" by the meaning of "fan(s)" thereof (Ma Zhonghong and Yang Changzheng 2016: 217). The creation of consonant words based on the word creation expressive needs constitutes a verbal play on sounds, whereby the most of the formed lexical units perform conative and emotive functions.

Graphically borrowed Words in the Russian-Language and Chinese-Language Internet Space

According to Russian linguists, a graphical borrowing means the reproduction of a borrowed word in the graphics of the donor language [Berkov, 2003, p. 4; Marinova, 2012, p. 96). Thus, a graphically borrowed word in the Russian language constitutes a lexical unit with the original graphics of another language.

Nowadays, it is typical to the Russian-language Internet to have national languages used with a large share of the English language components. The Internet communication in determining the events dynamics requires the means of nominating the newest 
concepts and realities. In case of the lack of nominative means in the original lexical reserves, foreign words perform the nominative functions becoming the graphically borrowed words. Many new graphically borrowed words may be found in the speeches of forum participants alongside with the phonetically borrowed words from the same foreign language source word. For example, trolling/mроллинг; lamer/лалер. According to E.V. Marinova, "it is typical for a foreign neologism to simultaneously exist in different graphic options, notably in the original (Latin) and the assumed (Cyrillic) ones" (Marinova, 2012, p. 100), the linguist considers the graphically borrowed word as "the primary form of lexical borrowing as well as the initial stage of mastering a foreign language neologism providing the transition thereof from the state of an inclusion to functioning in the system of the recipient language as a separate unit" (ibid.: 100).

There is another type of words in the modern Russian text with the graphically borrowed words or abbreviations as (mainly the first) component thereof, for example Aррмаркет (English Appmarket); chatланин (English Chat LANin); SIM-карта (English SIM card); SMS-сообщение (English SMS message); PIN-код (English PIN code); TV-шоу (English TV show); PR-ленеджер (English PR manager) (Krysin, 2010, p. 575). Some linguists consider them as complex words, others - as phrases consisting of an analytical adjective and a definable noun (Krysin, 2010, p. 577). Krysin argues that "modern Russian word formation prefers the creation of complex words of this kind, and one may consider the influence of the English language word-formation system therein, where such word-formation model is extremely common due to the universal nature thereof in forming the words of different parts of speech" (Krysin, 2010, p. 576).

The use of graphically borrowed words is influenced by the subjective sociopsychological factor of the discursive activity, notably the credibility of using foreign units in the native language (Marinova, 2012, p. 98). Such words like love, crazy, cool, good, new, happy (Forum "iXBT", 09.07.2001: http://forum.ixbt.com/topic.cgi?id=35:728) claim to be the usual foreign language inclusions while considering the communicative speech aspect. They may be qualified as communicatively labeled ones, since the use thereof is always correlated with a specific communicative situation and determined by the intentions of a writer.

We found some special graphically borrowed abbreviations by the first letters of the English phrases in the messages of the (Russian-language and Chinese-language) forums participants: IMHO (English In My Humble Opinion); BBS (English be back soon); pls / plz (English please); NP (English no problem) (Online Dictionary of Internet terms, Internet slang and jargon, 2018: http://internetrabota.net/), etc. These graphically borrowed abbreviations are well established among the Internet communicators; being a special speech formation, they allow native speakers to provide immediate responses to the conditions of communication.

Graphically borrowed lexical units may serve as means of forming new words created by the contamination thereof with the Russian language lexemes through a structural association. Hybrid graphic neologisms are formed within the language word creation and the play with graphics, while two source words and the meanings thereof are layered on the same material segment of language signs. For example, clubumbcr is formed due to the contamination of a graphical borrowed word club and the Russian word клубиться ("wreathe"); VIPендриваться = VIP ("very important person") + вылендриваться ("show off') (Prokutin, 2009: 124). The hybrid graphic neologisms differing not only by the arbitrary nature of intra-word boundaries but also by the semantic volume increase reflect the peculiarities of a speech situation. 
The Chinese language increasingly borrows "alphabetic words" (in relation to languages with the ideographic writing system) "fully written in letters of foreign (mainly Latin) alphabets or with the inclusion thereof" in recent times (Liu Yongquan, 2002, p. 85). We consider them as alphabetic words due to the graphic borrowing by the Chinese language.

Thus far, there is a wide variety of alphabetically borrowed words in the Chinese language. Based on the performed analysis of the Chinese-language Internet and taking into account the data of the Chinese linguist Liu Yongquan, the author of Dictionary of Letter Words (2001), we would like to note the main types of graphically borrowed alphabetic words in the Chinese language: 1) Borrowed abbreviations formed from the initial letters of all or some words phrases, notably PK (player killing); PhD (Philosophy Doctor). 2) Borrowed abbreviations formed from morphemes of a word or phrase, notably CP (couple); BGM (Background Music). 3) Borrowed full alphabetic words or expressions, notably hello; bye; pick; diss. 4) Borrowed abbreviations formed from the first letters of the first word of a phrase and the full second word of a phrase, notably e-mail (electronic mail); B-box (beat box).

Graphically borrowed alphabetic units are involved in the word-formation processes in the Chinese language. Combinations of alphabetic formations (including signs of the pinyin Chinese phonetic transcription based on the Latin alphabet) with the Chinese language hieroglyphs are generally called as mestizo words in the Chinese linguistics (混 血儿 (Liu Yongquan, 2002, p. 86)). We consider mestizo words in the Chinese language in the framework hereof as the words consisting of graphically borrowed alphabetic units and Chinese language components written in hieroglyphs.

The creation of mestizo words is implemented through the basic word-formation method of the Chinese language, notably stem-composition being predominant in the system of the Chinese language word formation. Complex mestizo words are formed combining foreign alphabetic and Chinese language hieroglyph components in the stemcomposition process through the word-formation models established in the Chinese language.

An attribute model is one of the most effective word-formation models in the Chinese language, according to which most of mestizo words are formed, where the first part of a complex word explains the second one. Therein, the stem-composition involves the alphabetical units borrowed both in the full spelling of the source words as well as in the abbreviated form thereof. For example, $C$ 位("central focus point, center of the whole group where someone is situated while taking group photos") $=\mathrm{C}$ (abbreviation from the English word center) + 位 ("place"); man力 (great strength, man power) = the English word man + 力 ("power”) (Baidu Encyclopedia, 2008: https://baike.baidu.com/).

A similar method of stem-composition is used in the modern Russian language, in particular, in the above-mentioned complex words such as Appмаркет (Appmarket), TVmoy (TV show), etc., where the first part constitutes a graphically borrowed component, and the second one constitutes a word written in Cyrillic with two parts combined as definition and definiendum, the graphically borrowed alphabetic component has a free location in the Chinese language mestizo words, for example, 大house ("big house": 大 "big" + English house), 小case ("petty matter, a mere nothing”: 小 “small” + English case) (Baidu Encyclopedia, 2008: https://baike.baidu.com/), where the alphabetic component is located in the second part and constitutes a definiendum. 
The performed analysis proves that apart from the attributive words, the Chinese language mestizo words may be formed from other types of word-formation structures common to the Chinese language but not existing in the Russian language word-formation system. The Chinese language words created by the stem-composition method may be divided into five main types: attributive, verbal-objective, verbal-effective, subjectpredicative and copulative ones depending on the type of relationship between the components thereof (Lu Zhiwei, 1965; Ren Xueliang, 1981).

In accordance with the verbal-objective communication structure between the parts of a word, the first component stands for an action and the second one stands for an object. We would like to provide some examples of the mestizo words formed in accordance with the objective model in the Chinese language: 立flag (literally meaning "put a flag") is used in the metaphorical meaning, notably "set a goal”) = 立 ("put") + flag; P图 ("handle graphic images") $=P$ (abbreviation for the English word Photoshop) + 图 ("photo, image"), where the first part $P$ is created through conversion, while $P$ (photoshop) is converted into the category of verbs from nouns by definition and obtains the meaning of "using the photoshop service" (Baidu Encyclopedia, 2008: https://baike.baidu.com/).

The first part of verbal-effective words stands for an action and the second one stands for an effect. Mestizo words may be formed in accordance with the effective model, for example, hold住 (“withstand, endure") = English hold + 住 (verbal effective suffix with the meaning of "tightly, firmly" emphasizing the conversion of an action into a steady state); get 到 (“understand, get an idea") = English get + 到 (“forming the verb effective form specifying the maximum effect of an action after the verbal stem") (Baidu Encyclopedia, 2008: https://baike.baidu.com/).

The subject-predicative words are formed due to the lexicalization of the sentences formed in accordance with the "subject-predicate" scheme. Two parts of this type mestizo words are in a predicative relation and evidence the object constant or variable features. For example: 个性open ("light-minded character of someone") = 个性 ("human character") + English open; 心情down (“mood fell down”) =心情 (“mood”) + English down (Baidu Encyclopedia, 2008: https://baike.baidu.com/).

The copulative type of stem-composition sometimes called as the composing model is characterized by the equality of the semantic relations of the word components. Graphically borrowed alphabetic units are also involved in the formation of mestizo words with copulative connection of the components. Let us provide an example: the word $Q$ 萌 (cute), where $Q$, an English letter consonant with the word cute, is used in the Chinese language in the meaning of “cute", and 萌 means “sweet, nice" (Baidu Encyclopedia, 2008: https://baike.baidu.com/).

New specific mestizo words appeared due to the hybridization of graphically borrowed alphabetical words and Chinese four-syllable idioms based on sound similarity of an alphabetic word with some components (or one component) of the Chinese idiom are especially popular in the Chinese-language Internet in recent times. For example, 无fuck 说 is formed by hybridization of the English obscene word fuck and the Chinese idiom 话可说 ("there are no words for that, nothing to say"), therewith the components 话 [hua], 可 [ke] in the Chinese language southern dialect are consonant to the English word fuck. The layering of the two source words meanings in the mestizo word 无fuck 说 provides a stronger emotive aspect: the word fuck is characterized by an emphatic expressive 
K. Zhang, et al.

connotation of roughness performing the function of a phonetic pun and having a humorous effect: the word as a whole has a double meaning - the word is phonetically understood as the original Chinese idiom无话可说 in the meaning of "nothing to say", but it literally means "there are no words for that, even the obscene ones" in accordance with the graphical form thereof. This word creation method is similar to the contamination considered above used for creating hybrid graphic neologisms in the modern Russian language by the Latin and Cyrillic means.

The overlaid part sometimes coincides by semantic content with the contamination of the alphabetic letters and Chinese idioms, for example, in the mestizo words 半tour 废( the English word tour play in the structure of the Chinese idiom半途而废 “stop halfway"), where the alphabetic word tour and the overlaid components 途 [tu], 而 [er] of the original Chinese idiom are similar not only in the sound but also in the meaning thereof. The neologism 半tour 废 is used in the same meaning of the Chinese idiom, however, it has some features of novelty and unfamiliarity (Baidu Encyclopedia, 2008: https://baike.baidu.com/).

\section{CONCLUSION}

As we can see both the Russian and Chinese languages borrow foreign words in accordance with the phonetic, semantic and graphic methods. An important feature of the newest borrowed words used by the Russian and Chinese Internet users is that predominantly American English constitutes the source language.

Most of the borrowed Russian words having new language semantics are phonetically borrowed. They are borrowed in the sound form and in the meaning similar to the prototype one. In distinction from the Russian language, the Chinese language most often borrows new terms by the method of calquing due to the semantic significance of each hieroglyph syllable thereof.

There is a tendency of increase in the number of phonetically borrowed words having semantic equivalents in the common language both in the Russian-language and in the Chinese-language Internet communication space. They perform the expressive function preserving the effect of novelty and fashion by their form. Some specific phonetically borrowed words are popular in the Chinese Internet for providing the enhanced level of expression created by choosing the hieroglyphs consonant with the source words in such a way that this phrase assumes a comic connotation.

The adoption of a new meaning by the Russian and Chinese language words may be based on the sound similarity of the calqued word and the foreign-language prototype thereof. We refer such words to a special type of the lexical calques appeared due to the play on sounds based on the phonetic association.

Different English words and phrases become a part of the Russian and Chinese texts and become graphically borrowed units while preserving their original Latin graphics. Some graphically borrowed lexical units participate in the stem-composition in the Russian and Chinese languages. As a result, the first part of the Russian language complex word constitutes a graphically borrowed component, and the second one constitutes a word written in Cyrillic with two parts combined as definition and definiendum. This type of words is apparently formed under the influence of a similar word-formation model in the English language. And the Chinese language mestizo words' graphically borrowed components and the Chinese language components written in 
hieroglyphs may be implemented in accordance with a free location in five types of relations, notably the attributive, verbal-objective, verbal-effective, subject-predicative and copulative ones. These word-formation structure types are common to the Chinese language system.

Graphically borrowed lexical units may serve as means for creating lexical neologisms in the Russian and Chinese languages distributed in the Internet for the emotive and evocative expression of users as well as their creative self-expression. The Russian language hybrid graphical neologisms are formed by contaminating the graphically borrowed units and Russian language lexemes through a structural association, and the Chinese language ones are formed by hybridization of the graphically borrowed alphabetic words and Chinese four-syllable idioms based on the sound similarity of an alphabetic word with some components (or one component) of the Chinese idiom.

Thus, the contrastive-comparative analysis of different borrowing (phonetic, semantic, graphic) methods of foreign words in the Russian and Chinese languages proves that the newest borrowed words applied by the Internet communication users have the features of the conversation vocabulary.

\section{ACKNOWLEDGEMENT}

The publication has been prepared with the support of the "RUDN University Program 5-100". The reported study was funded by RFBR and the government of Volgograd region according to the research project № 18-413-342007.

\section{REFERENCES}

Aleshchanova, I. V., Frolova, N. A., \& Zheltukhina, M. R. (2018). Evolution of Motives in Professional Personality Formation: Foreign Language Learning Context. In: Proceedings of the International Conference on the Theory and Practice of Personality Formation in Modern Society (Ictppfms 2018), 198, pp. 35-40.

Avanesov, R. I., \& Ozhegov, S. I. (2007). Russian spelling dictionary: about 180000 words. Russian Academy of Sciences. Institute of Russian Language. V. Vinogradova, O. E. Ivanova, V. V. Lopatin (ed.), I. V. Nechaev, L. K. Cheltsov. Moscow: Institute of Russian Language named after V. V. Vinogradov. 943 p. [Online] Retrieved on 06.05.2018 from http://wordsonline.ru/

Baidu Encyclopedia. (2008). [Online] Retrieved on 12.05.2018 https://baike.baidu.com/

Berkov, V. P. (2003). From observations on changes in modern European languages. In:

Modern language processes. SPB: SPB University Press, pp. 3-22.

Bussmann, H. (1999). Routledge Dictionary of Language and Linguistics. Beijing: Foreign Language Teaching and Research Press.

Bynon, T. 1977. Historical linguistics. Cambridge: Cambridge University Press. https://doi.org/10.1017/CBO9781139165709

Crystal, D. (2008). A Dictionary of Linguistics and Phonetics. London: Wiley-Blackwell. https://doi.org/10.1002/9781444302776

Duanmu, S. (2007). The Phonology of Standard Chinese. Oxford: Oxford University Press. Forum "iXBT". (2001). Other forums. Overall. (09.07.2001) [Online] Retrieved on 10.06.2018 from http://forum.ixbt.com/

Gao, M., \& Liu, Z. (1958). The study of loan words in modern Chinese. Beijing: Publishing Writing Reform.

Ge Benyi. (2002). Lexicology of the modern Chinese language. Jinan: Shandong People's Publishing House. 
K. Zhang, et al.

Haugen, E. (1950). The Analysis of Linguistic Borrowing. Language, 26(2), 210-231. https://doi.org/10.2307/410058

Hu, P. (2004). Adapting English into Chinese. English Today, 20(2), 34-39. https://doi.org/10.1017/S0266078404002068

$\mathrm{Hu}, \mathrm{Q}$., \& Xu, J. (2003). Semantic Transliteration. A Good Tradition in Translating Foreign Words into Chinese. Babel, 49(4), 310-326. https://doi.org/10.1075/babel.49.4.04qin

Krysin, L. P. (2004). Russian word, his and others': Studies in the modern Russian language and sociolinguistics. Moscow: Languages Slavic culture Publ. 888 p.

Krysin, L. P. (2010). About some new types of words in the Russian language: wordscentaurs. Bulletin of the Nizhny Novgorod University n.a. N.I. Lobachevsky Linguistics, 4(2), 575-579.

Kuznetsov, S. A. (2014). Great explanatory dictionary of Russian language. 1st ed. SPb.: Norint, 1998. Retrieved on 08.06.2018 from http://gramota.ru/

Liu, Y. (2001). Dictionary of letter words. Shanghai: Shanghai Lexicographical Publishing House.

Liu, Y. (2002). Personal letters problems in Chinese. Language application, 1, 85-90.

Liu, Z., Gao, M., Mai, Y., \& Shi, Y. (1984). Dictionary of Loanwords in Chinese. Shanghai: Shanghai Lexicographical Publishing House.

Lo, C., \& Hu, S. (2009). Language and culture. Beijing: Beijing University Press.

Lu, Z. (1965). Word formation in Chinese. Beijing: Science Press.

Ma, Z., \& Yang, C. (2016). New Media · New Youth · New Culture: A Study of the Popular Culture Phenomenon of Chinese Youth Network. Beijing: Tinghua University Press.

Marinova, E. V. (2012). Foreign Vocabulary of the modern Russian language: study guide. Moscow: Flint Publ.

Miao, R. (2005). Loanword Adaptation in Mandarin Chinese: Perceptual, Phonological and Sociolinguistic Factors (Dissertation for the Degree of Doctor of Philosophy in Linguistics), Ruiqin Miao. Stony Brook University.

Minakova, N. A., Ponomarenko E. B., \& Talibina E. V. (2018). About three groups of loanwords of mass media language (on the material of Moscow newspapers). Scientific and practical journal. Modern science: actual problems of theory and practice, The Humanities series, (4), 139-143.

Modern Chinese Dictionary. (2016). Dictionary Compilers from Language Research Group of Chinese Social Science Institute ed. Beijing: Commercial Press. 7th ed. Retrieved on 12.05.2018 from http://www.cidianwang.com/

Obara, J. (1989). Theoretical problems of tracing. Wrocław: Acta Universitatis Wratislaviensis.

Online Dictionary of Internet Terms, Internet Slang and Jargon. (2018). Retrieved on 15.05.2018 from http://internetrabota.net/

Online Dictionary of Modern Vocabulary, Jargon and Slang. (2014). Retrieved on 10.05.2018 from https://argo.academic.ru/

Prokutin, E. V. (2009). Language game as a way to form non-standard Russian vocabulary based on English borrowing. Bulletin of Chelyabinsk State University, Philology. Art Criticism, 7(188), Issue 41, 123-127.

Reformatsky, A. A. (1996). Introduction to linguistics. Moscow: Aspect-Press.

Ren, X. (1981). Word formation of the Chinese language. Beijing: China Social Sci. Press.

Richards, J. C., \& Schmidt R. W. (2010). Longman Dictionary of Language Teaching and Applied Linguistics. London: Longman Group UK Ltd. 
Online Journal of Communication and Media Technologies, 2019

Sapir, E. (2006). Language: An Intro. to the Study of Speech. Middlesex: Echo Library.

Semenas, A. L. (2000). Vocabulary of Chinese. Moscow: Muravej.

Shi, Y. (2004). Loanwords - Agents of the Alien Culture. Changchun: Jilin Edu. Press.

Shi, Y. (2013). Loanwords in Chinese. Beijing: Commercial Press. https://doi.org/10.1086/ 668898

Tameryan, T. Yu., Zheltukhina, M. R., Sidorova, I. G., \& Shishkina, E. V. (2019). Stereotype Component in the Structure of Ethnocultural Archetype (On InternetBlogs). The European Proceedings of Social \& Behavioural Sciences, 200, 1716-1722. https://doi.org/10.15405/epsbs.2019.03.02.200

Tameryan, T. Yu., Zheltukhina, M. R., Slyshkin, G. G., Abakumova, O. B., Volskaya, N. N., \& Nikolaeva, A. V. (2018a). Metaphor in Political Media Discourse: Mental Political Leader Portrait. Online Journal of Communication and Media Technologies, 8(4), 377-384. https://doi.org/10.12973/ojcmt/3958

Tameryan, T. Yu., Zheltukhina, M. R., Slyshkin, G. G., Shevchenko, A. V., Katermina, V. V., Sausheva, Ye. V. (2018b). New Country's Political Discourse: Formation of Speech Technologies. Modern Journal of Language Teaching Methods, 8(7), 151-160.

Volskaya, N. N., Tameryan, T. Yu., Zheltukhina, M. R., Boeva-Omelechko, N. B., Komleva, L. A., \& Knyazeva, Ye. G. (2018). Literary Translation as Cognitive Overlap between Foreign and Native Languages. Modern Journal of Language Teaching Methods, 8(7), 161-172.

Wang, L. (2012). Xinhua Network Language Dictionary. Beijing: Commercial Press. Retrieved on 12.05.2018 from http://www.cidianwang.com/

Zhang, K., \& Denisenko, V. N. (2018). Computer and network word in the Russianlanguage and Chinese-language communicative internet space. RUDN Journal of Language Studies, Semiotics and Semantics, (4), 200-215. https://doi.org/10.22363/2313-2299-2018-9-4-911-925

Zhao, Y. (2012). The phenomenon of ambiguity in Chinese. Linguistics thesis collection, 820-835.

Zheltukhina, M. R. (2010). The role of information in media discourse. In: Bulletin of the Center for International Education of Moscow State University. Philology. Culturology. Pedagogy. Technique, 3, 12-18.

Zheltukhina, M. R., Bondareva, N. V., Zelenskaya, L. L., Anikeeva, I. G., Malygina, L. E. \& Chistyakov, A. V. (2019). Media Promotion Role of Economic Vocabulary: Specific Features and Functions in Presentation and Advertisement. Online Journal of Communication and Media Tech., 9(2), e201907. https://doi.org/10.29333/ojcmt/5733

Zheltukhina, M. R., Klushina, N. I., Ponomarenko, E. B., Vasilkova, N. N., \& Dzyubenko, A. I. (2017). Modern Media Influence: Mass Culture - Mass Consciousness - Mass Communication. XLinguae Journal, 10(4), 96-105. https://doi.org/10.18355/XL.2017. 10.04.09

Zheltukhina, M. R., Ukrainskaya, A. V., Ponomarenko, E. B., Fanyan, N. YU., \& Talybina, E. V. (2018). Stylistic means of Influence in the contemporary Chinese sports media advertising. XLinguae Journal, 11(1), 152-162. https://doi.org/10.18355/XL.2018.11. 01.14

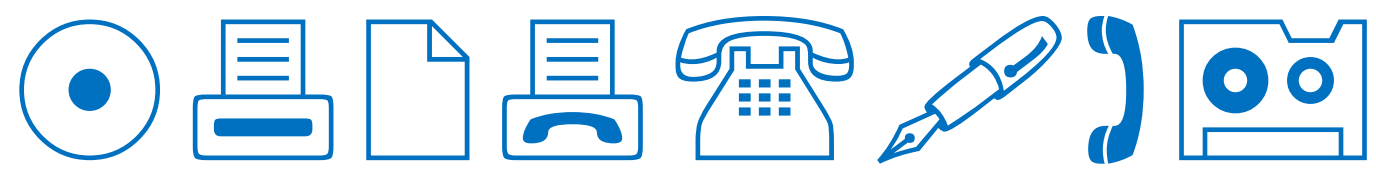

